\title{
CAPÍTULO XXI
}

\section{CRISE CIVILIZATÓRIA E A NECESSÁRIA RUPTURA DA ORDEM VIGENTE}

\author{
DOI: $h t t p: / / d x . d o i . o r g / 10.18616 / p l a n 21$ \\ Danilo Barbosa de Arruda - UNESC \\ Geraldo Milioli - UNESC
}




\section{INTRODUÇÃO}

A crise ecossistêmica tem dado sinais da falência do modus operandi capitalista. Nesse cenário, acentua-se o paradoxo diante de uma sociedade interligada, baseada em farta tecnologia e equipamentos de ponta, com produção de riquezas, mas que não sabe resolver questões elementares de distribuição de renda e oportunidade, com precária gestão ambiental, uso indiscriminado dos recursos naturais, tornando a Terra um lugar cada vez mais hostil à própria espécie humana.

Na outra ponta, para tentar mitigar os efeitos adversos do sistema produtivo e suas implicações socioambientais, surgem os pressupostos de uma nova era pautada pela racionalidade ambiental, por uma ética da vida, pelo bem viver e efetivação dos direitos humanos e sociais. A desigualdade e formas de dominação existentes entre países desenvolvidos (Norte) e subdesenvolvidos (Sul) são evidenciadas pela macroeconomia, destruição de recursos naturais, colapso social e transformações oriundas de decisões político-econômicas. Desse modo, provoca uma retroalimentação da relação de poder entre ricos e pobres, opressão, utilitarismo, consumismo e individualismo pregados pelas mídias.

No entanto, guardada as proporções e imperfeições do artigo em comento, até por questões de delimitação de conteúdo, é notável o desfecho das turbulências que assolam os seres humanos e a biodiversidade, decorrentes do modelo de produção adotado na maioria dos países do mundo. Na era da globalização um enorme contingente de materiais, pessoas, serviços e produtos transitam num fluxo acelerado. Esse fluxo decorrente do mercado internacional e nacional gera inúmeros efeitos colaterais para a sociobiodiversidade.

O meio ambiente agoniza com a velocidade de retirada de insumos que é superior à reposição natural dos recursos energéticos mostrando a incompatibilidade do crescimento econômico ad infinitum. Direitos humanos e sociais são renegados em prol do crescimento econômico e da manutenção do establishment atual, quase sempre traduzido num Produto Interno Bruto que não atende as reais necessidades dos países exportadores de commodities ${ }^{23}$. Nessa toada, com a dinâmica da globalização no século XXI, há um exacerbado aumento das incongruências entre a sustentabilidade, sociedade, economia e meio ambiente conduzindo a conflitos em diversas escalas e pondo em risco a vida.

\section{RELAÇÕES DE PODER ENTRE PAIISES DO NORTE E DO SUL: ASSIMETRIAS E AMBIVALÊNCIAS}

As relações de poder existentes na atualidade consolidaram-se ao longo do tempo e dos ciclos econômicos, bem como de circulação do capital. Após as revoluções industriais e Segunda Guerra Mundial constituiu-se um seleto grupo de países que ditou os rumos de boa parte do restante do mundo. O poderio bélico, econômico, científico, político e cultural de Europa, Estados Unidos, Japão e alguns países esparsos no globo trouxeram uma hegemonia por parte destes em detrimento dos demais. Um dos resultados decorrentes dessas relações divergentes de poder é

\footnotetext{
${ }^{23}$ Para melhor compreensão, as commodities tradicionais (ou convencionais) são mercadorias padronizadas para compra e venda. É tudo o que está na prateleira do supermercado. Por exemplo, encontram-se, dentre as commodities tradicionais, garrafas de água mineral, todas iguais e com a mesma quantidade, mesmo critério de engarrafamento, mesmo tratamento fitossanitário. $O$ consumidor que compra uma commodity tradicional exige certificado de qualidade, selos que comprovem a fiscalização sanitária e, nos dias de hoje, questiona-se se trata de alimentos transgênicos ou orgânicos. Para ser uma commodity, o produto passa por uma série de exigências de comercialização, tributação e transporte, além de enfrentar negociações com os agentes internacionais na sua colocação no mercado externo. A commodity disputa espaço enfrentando embargos, barreiras tarifárias e não-tarifárias (EL KHALILI, 2009, p. 58).
} 
em relação aos países subdesenvolvidos ou em desenvolvimento, dito países do Sul. Os países que se encontram abaixo da linha do Equador, os do Sul, têm várias características em comum.

Perante esse complexo de transformações, mudanças, adaptação cultural sob a batuta de conflitos e tensões, ondas de imigrações, guerras, crise hídrica, extremos climáticos e outros que ensejaram a definição de natureza e o tipo de relação exercido em relação a ela no mundo moderno. Seja uma relação de convivência harmônica e sentimento de pertencer a ela e dela ser parte, com uma visão holística e integradora da parte no todo e vice-versa, ou modernamente, uma relação de dominação, de destrutividade e de separação do que é natural ou advindo da natureza dos demais elementos construídos e elaborados na atualidade (GONÇALVES, 2002, p.96).

Dentre as mudanças e transformações radicais que assolam o mundo, em sua maior parte, há que se considerar um impacto maior para os países pobres. Essa complexidade ambiental exige uma racionalidade no Sul que possuem problemas e oportunidades semelhantes: uma ampla riqueza ambiental, desigualdades ${ }^{24}$ sociais acentuadas, problemas ambientais, conflitos internos, disparidades regionais e uma gama de especificidades que todos, em maior ou menor grau, compartilham como herança da colonização. Sendo assim, as assimetrias são evidentes e há que se procurar entender as causas e consequências disso. Além da origem das questões entre Norte e Sul, há uma ambivalência das relações de poder que são perpetuadas ou maquiadas ao longo dos séculos para manter a dominação ideológica, política, social, econômica, educacional, social, civil. O comércio internacional, a perpetuação ideológica e cultural da globalização ${ }^{25}$ geram mais injustiças nas nações da América Latina, Ásia e África consubstanciam esse ciclo de exploração das riquezas e socialização dos custos ambientais ${ }^{26}$.

Os prejuízos ambientais oriundos da usurpação dos ativos ambientais encontrados nos países pobres têm dado suporte a uma economia ${ }^{27}$ voraz. A velocidade de exploração é superior a capacidade de recarga e reposição por parte dos sistemas naturais, seus biomas e ecossistemas. $A$ transformação da paisagem ${ }^{28}$ têm sido absurdamente rápida e isso tem provocado impactos das mais variadas ordens e dimensões. No que tange ao tema das mudanças climáticas, despertou um debate rico que afeta diretamente países pobres, pois são os mais vulneráveis e com problemas

\footnotetext{
${ }^{24} \mathrm{O}$ resultado dessas contradições é antes o aprofundamento do que a atenuação dos desenvolvimentos geográficos desiguais em suas dimensões tanto políticas como econômicas. A extensão de todo tipo de sistema de dominação pelo Estado reduz zonas inteiras do globo e vários estratos de população que ali vivem a condições próximas da escravidão. E a concentração de recursos, principalmente públicos, no espaço produz uma espiral de desigualdades geográficas em todas as escalas. E tudo isso no interesse da preservação das fontes político-econômicas do poder do Estado que garantem o funcionamento dos livre mercados. Os paradoxos e contradições se evidenciam em toda parte (HARVEY, 2009, p.238).

${ }^{25}$ Neste sentido, o conceito de ambiente se defronta com as estratégias fatais da globalização. O princípio de sustentabilidade surge como uma resposta à fratura da razão modernizadora e como uma condição para construir uma nova racionalidade produtiva, fundada no potencial ecológico e em novos sentidos de civilização a partir da diversidade cultural do gênero humano. Trata-se da reapropriação da natureza e da reinvenção do mundo; não só de "um mundo no qual caibam muitos mundos", mas de um mundo conformado por uma diversidade de mundos, abrindo o cerco da ordem econômico-ecológica globalizada (LEFF, 2011, p.31).

${ }^{26}$ Assim, a internalização dos custos ecológicos e das condições ambientais da produção implica a necessidade de caracterizar os processos sociais que determinam o valor da natureza. A revalorização da natureza induzida pelo ambientalismo emergente está se refletindo na economia pela alta dos preços dos recursos e dos custos ambientais. Porém, o movimento ambiental não só transmite os custos ecológicos ao sistema econômico como uma resistência à capitalização da natureza; as lutas sociais para meIhorar as condições de sustentabilidade e a qualidade de vida abrem um processo de reapropriação social da natureza. Portanto, o ambientalismo está propondo tanto a descentralização do processo de desenvolvimento como uma reconstrução das próprias bases do processo produtivo (LEFF, 2011, p.66).

${ }^{27}$ É a relação com o não-econômico que falta a ciência econômica. Essa é uma ciência cuja matematização e a formalização são cada vez mais rigorosas e sofisticadas; mas essas qualidades contêm o defeito de uma abstração que se separa do contexto (social, cultural, político); ela conquista sua precisão formal esquecendo a complexidade de sua situação real, ou seja, esquecendo que a economia depende daquilo que depende dela. Assim, o saber economicista que se encerra no econômico torna-se incapaz de prever suas perturbações e seu devir, e torna-se cego ao próprio econômico (MORIN; KERN, 1995, p.70)

${ }^{28} \mathrm{~A}$ paisagem resulta de um somatório de diferentes elementos, das formas como se inter-relacionam, de informações complexas, de inúmeras formas de percepção isoladas e de visões analíticas. Ela envolve questões físicas, atuais ou pretéritas, a gênese de aspectos como a formação geológica e geomorfológica, a diversidade de formas de relevo, a compartimentação geográfica e hidrológica, registros de acontecimentos paleoclimáticos e vegetacionais de capital importância para o conhecimento da história do planeta, marcas deixadas por povos pré-históricos, assim como, os efeitos provocados pelas ações do homem moderno (DELPHIM, 2005, p.4).
} 
congênitos. Lançando o premente questionamento, quem vai pagar para amenizar os efeitos que as alterações do clima vão gerar nos países que, diferentemente dos que se tornaram ricos ao longo dos tempos, emitiram muito menos gases de efeito estufa? Esse aspecto permanece em discussão e é um dos mais polêmicos, dada a resistência dos países que mais emitiram no passado- leia-se EUA, Europa e Japão- em financiar os estragos nos países mais pobres (RIBEIRO, 2010, p.77).

Nessa toada, as assimetrias são reais e têm consequências para a sociedade, biodiversidade, a própria economia no longo prazo e contribui para relações de poder desiguais entre os países do Norte e Sul:

\begin{abstract}
Observa-se que os recursos naturais não são usados pela maioria dos países pobres para o seu desenvolvimento e melhoria da qualidade e padrão de vida de seus habitantes, mas para atender exigências financeiras dos países industrializados e credores, suscitando, por conseguinte, problemas de sustentabilidade sócio-econômica, política e ambiental. Diante desta realidade, torna-se ainda mais relevante o papel dos organismos internacionais, dos fluxos financeiros, do comércio exterior, dos investimentos transnacionais, da transferência de tecnologia e das cooperações multi e bilaterais. Mas é lógico que esta não é uma questão fácil quando se pensa em expansão, taxas de juros, avanço do protecionismo, níveis de consumo e desigualdades, etc. Porém, o que parece estar em jogo, nesse momento, é a necessidade de se sair de ajustes puramente econômicos para as dimensões ecológicas, negligenciadas no passado e de alcance incipiente no presente (MILIOLI, 1999, p.80).
\end{abstract}

Assim, o bem estar dos países do Norte é advindo, em parte, da exploração, devastação e degradação dos recursos minerais e energéticos nos países do Sul. As externalidades ambientais ${ }^{29}$, o passivo deixado pelas transnacionais fica nos países pobres e todo sortilégio de implicações para os direitos humanos, econômicos, sociais e ambientais. O real valor de cada produto, serviço e mercadoria não é devidamente pago, pois o verdadeiro custo não está embutido. É necessário rever esse conceito de não incutir após as transformações dos recursos naturais, o seu preço equivalente desde a extração. Ademais, reprogramar a lógica do modelo capitalista de produção para uma nova era de imperial necessidade com a vida em todas as suas formas. Diminuir insumos, substituir tecnologias, é o que afirma o excerto a seguir:

Todavia, o discurso da sustentabilidade chegou a afirmar o propósito e a possibilidade de conseguir um crescimento econômico sustentado através dos mecanismos do mercado, sem justificar sua capacidade de internalizar as condições de sustentabilidade ecológica, nem de resolver a tradução dos diversos processos que constituem o ambiente (tempos ecológicos de produtividade e regeneração da natureza, valores culturais e humanos, critérios qualitativos que definem a qualidade de vida) em valores e medições dos mercado (LEFF, 2011, p.11).

A ambivalência entre manter o status quo com todas as suas idiossincrasias e investir num futuro que assegure a sobrevivência humana, a manutenção dos ecossistemas, e um novo

\footnotetext{
${ }^{29}$ Porém, o conceito de ambiente cobra um sentido estratégico no processo político de supressão das "externalidades do desenvolvimento"- a exploração econômica da natureza, a degradação ambiental, a desigual distribuição social dos custos ecológicos e a marginalização social- que persistem apesar da ecologização dos processos produtivos e capitalização da natureza (LEFF, 2011, p.19).
} 
ritmo socioeconômico requer um trabalho de envergadura que perpassa a interdisciplinaridade e a visão holística da sustentabilidade para abarcar todos os seres vivos, contemplar sua efetiva proteção, restauração e melhorias. Entretanto, o que tem se confirmado ao longo das últimas décadas é um retrocesso na seara da partilha dos bens e riquezas produzidas mundialmente. Pelo contrário, há um aumento considerável de uma elite que concentra, cada vez mais, poder econômico-financeiro:

Degradação social decorrente do processo de globalização e neoliberalismo implica a perda parcial ou total do status social, a exclusão dos direitos a que todo indivíduo tem na sociedade, levando, quase sempre, à marginalidade e/ou marginalização daqueles que não possuem a materialidade desses direitos (RATTNER, 1995, 60-65).

Na mesma esteira, o excerto adiante endossa essa profunda ilusão do capitalismo como único sistema viável num planeta em demasiada crise de valores, em permanente extinção de espécies, envolto em poluição, guerras, conflitos, escassez de água, migrações forçadas e desastres climáticos:

A realidade do sistema e suas promessas são incompatíveis, afinal a desigualdade, a competição, o acúmulo, privilégios e concentração de renda são inerentes ao capitalismo. Sem distinção de classes, sem diferenças sociais, poderio econômico versus pobreza e marginalização o sistema entra em declínio. Logo, os ideais prometidos no capitalismo se anulam, pois o inviabilizam, caso liberdade e igualdade sejam oportunizados a todos de maneira concreta. Esses conceitos e valores são reais e objetivos, organicamente gerados pelo próprio sistema de mercado e dialeticamente ligados a ele de maneira indissociável. O sistema é mantido e perpetuado graças à desigualdade, acúmulo, retroalimentando as mazelas sociais de uma esmagadora maioria para incrementar o rendimento e privilégios de poucos (JAMESON, 1996, p. 280).

A humanidade na contemporaneidade está imersa num espectro complexo de problemas. A globalização aproximou e, ao mesmo tempo, afastou ainda mais os ricos dos pobres, os imigrantes indesejados dos ricos turistas, os países ricos e desenvolvidos dos pobres subdesenvolvidos. Tornando latente questões étnicas, culturais, de interesse geopolítico, conflitos internos e externos, deixando em perspectiva os fatores que engendraram esse $\operatorname{caos}^{30}$. O colapso da internacionalização para os direitos humanos advém do eufemismo da flexibilização dos direitos trabalhistas, da usurpação de direitos e garantias constitucionais, da rejeição ao capital natural, da desvalorização do meio ambiente, da supremacia do ter em detrimento do ser:

Por fim, o excerto adiante põe em evidência sempre que, em questões políticas, o são juízo humano fracassa ou renuncia à tentativa de fornecer respostas, nos deparamos com uma crise. Crise esta engendrada pela civilização humana, multifacetada, pois abarca um

\footnotetext{
${ }^{30} \mathrm{Na}$ percepção desta crise ecológica foi sendo configurado um conceito de ambiente como uma nova visão do desenvolvimento humano, que reintegra os valores e potenciais da natureza, as externalidades sociais, os saberes subjugados e a complexidade do mundo negados pela racionalidade mecanicista, simplificadora, unidimensional e fragmentadora que conduziu o processo de modernização. $\mathrm{O}$ ambiente emerge como um saber reintegrador da diversidade, de novos valores éticos e estéticos e dos potenciais sinergéticos gerados pela articulação de processos ecológicos, tecnológicos e culturais. O saber ambiental ocupa seu lugar no vazio deixado pelo progresso da racionalidade científica, como sintoma de sua falta de conhecimento e como sinal de um processo interminável de produção teórica e de ações práticas orientadas por uma utopia: a construção de um mundo sustentável, democrático, igualitário e diverso (LEFF, 1986).
} 
sortilégio de aspectos da vida, incluindo seu próprio fim. Essa espécie de juízo é, na realidade, aquele senso comum em virtude do qual nós e nossos cinco sentidos individuais estão adaptados a um único mundo comum a todos nós. O desaparecimento do senso comum nos dias atuais é o sinal mais seguro da crise atual. Em toda crise, é destruída uma parte do mundo, alguma coisa comum a todos nós, isso é claramente demonstrado nos atos que excluem, denigrem, marginalizam, subjugam ou incutem no semelhante que ele é diferente, tipificando-o como uma ameaça, inferior ou passível de extermínio pelo simples fato de não comungar da mesma língua, traços físicos, vestimentas, dentre outros (ARENDT, 1972, p.227).

A crise civilizacional atinge todos, em maior e menor grau, dependendo de fatores como renda, cultura, acesso, território, país de origem, mas está impregnada na sociedade, meio ambiente e economia da humanidade, como um todo. Perfaz, assim, um desolador espectro conjuntural que está desgastando conceito de desenvolvimento sustentável. Pois, o termo politicamente cunhado para perpetuar com menos agressividade o modelo capitalista, mas não alterar sua base e funções essenciais, tem sofrido críticas pelo demasiado uso da palavra como se fosse mágica. Até porque não há um consenso quanto ao adjetivo sustentável, relação desigual NorteSul modelo insustentável de produção e consumo ocidental e todas as suas mazelas.

Diante do exposto, há que se reconhecer que existem vários tipos de desenvolvimento sustentável para cada região e de acordo com as especificidades de um bioma, cultura e povo. Não se ater ao simples uso do adjetivo como panacéia, mas sim como um recorte político-ideológico capaz de superar com outros mecanismos as dicotomias Norte-Sul. Deve-se analisar criticamente o uso de tecnologias para combater externalidades ambientais de oriundas processos tecnológicos diversos, consoante um estilo alternativo de desenvolvimento renunciando ao crescimento ecológico ilimitado obstando o ritmo de degradação ambiental (DIEGUES, 1992):

\footnotetext{
A ideologia capitalista difundiu de forma única que a vida seria melhor, muita riqueza seria gerada e, óbvio, espalhada, que os produtos, mercadorias e serviços trariam felicidade e acabariam com os problemas existentes na sociedade. No entanto, para grande maioria das pessoas ao redor do mundo, a globalização acentuou ambivalências já existentes entre os povos e as questões latentes se acirraram, havendo um exponencial aumento da crise planetária de refugiados do clima, economias em colapso, guerras, perseguições políticas e religiosas. Não obstante, dentro das nações e entre elas também houve um significativo aumento das trocas, comunicação, mas é preciso a compreensão entre os seres humanos. Além disso, fazer ciência para os seres vivos e não para maximização do lucro e acumulação por poucos indivíduos e famílias (MORIN, 2002, p.50).
}

Não obstante, a mitigação dos direitos humanos, a flexibilização e retirada de direitos trabalhistas e sociais historicamente adquiridos, as externalidades ambientais e os passivos ecológicos causados pela própria sociedade, iniciativa privada e Estado sob a batuta do dito progresso e desenvolvimento têm conduzido os povos a um extermínio das outras espécies e condições de vida para manutenção até mesmo dos elementos essenciais ao homem. Com a socialização dos custos ambientais e a privatização dos lucros, a questão ambiental passa ser vista na sua completude já que não é somente técnica, mas sobretudo político-ideológica, com uma práxis recorrente e pulverizada como "natural". Sobretudo, depende de interesse político e investimento público e diz respeito às divergentes posições do social, ambiental e econômico. 
A eliminação da expoliação de recursos do Sul para o Norte, com seus interesses hegemônicos para construir uma sociedade sustentável levando em consideração suas necessidades e conhecimentos, as idiossincrasias dos países em desenvolvimento, deixando de lado o padrão das sociedades altamente industrializadas do Norte e seu modelo único calcado na economia de mercado irrestrito, com sociedade e meio ambiente em plano de fundo para alcance do extraordinário lucro dos banqueiros e investidores (DIEGUES, 1992).

\section{DIREITOS HUMANOS E GLOBALIZAÇÃO EM PERSPECTIVA NA CONTEMPORANEIDADE}

Os direitos humanos foram sendo adquiridos, construídos e ordenados sistematicamente ao longo dos séculos. É uma invenção social e faz parte do direito ocidental que visa corroborar para a consecução de objetivos concretos para a comunidade componente num dado espaço, tempo e regida por ordenamento pátrio participante. Não obstante, os tempos modernos recrudesceram alguns sentimentos latentes que estavam em dormência desde a configuração da Europa e Estados Unidos da América como exemplos impostos pela Organização das Nações Unidas (ONU), Fundo Monetário Internacional (FMI), Banco Mundial, Banco Interamericano de Desenvolvimento (BID), sendo decorrência direta das duas Grandes Guerras ${ }^{31}$ e dos programas estratégicos de polarização mundial que se seguiram.

Nesse diapasão, houve uma reformulação do Estado de bem estar social para um Estado liberal, agora neoliberal ${ }^{32}$, que aprofunda e torna nítido as questões entre classes no capitalismo vigente:

As misérias do tempo de guerra e do pós-guerra deram lugar ao consumo desenfreado, ao crescimento industrial e urbano das cidades, à consequente poluição do ar, solo e águas, e aos constrangimentos da natureza. Todas estas mazelas da cidade industrial e dos modos de vida moderno fizeram com que alguns grupos de pessoas percebessem que a poluição das cidades e a diminuição da biodiversidade apontam o aquecimento global, e a destruição da camada de ozônio, constatando que a catástrofe ambiental é evidente. Mesmo assim, a industrialização e o consumo continuam a saga de degradação, utilizam recursos naturais dos países em desenvolvimento, impactam a natureza, poluem cidades e alteram o clima da Terra (OLIVEIRA; MILIOLI, 2014, p.75).

As implicações advindas da rápida urbanização e da industrialização desordenada, aliado a outros fatores histórico, sociais, econômicos e culturais, corroboram com modus operandi do capitalismo para a catástrofe ambiental. Some-se a isso o alto consumo dos países ricos em matérias-primas e insumos, produtos e serviços que são explorados nos países em desenvolvimento afetando diretamente a população já negligenciada:

\footnotetext{
${ }^{31}$ As misérias do tempo de guerra e do pós-guerra deram lugar ao consumo desenfreado, ao crescimento industrial e urbano das cidades, à consequente poluição do ar, solo e águas, e aos constrangimentos da natureza. Todas estas mazelas da cidade industrial e dos modos de vida moderno fizeram com que alguns grupos de pessoas percebessem que a poluição das cidades e a diminuição da biodiversidade apontam o aquecimento global, e a destruição da camada de ozônio, constatando que a catástrofe ambiental é evidente. Mesmo assim, a industrialização e o consumo continuam a saga de degradação, utilizam recursos naturais dos países em desenvolvimento, impactam a natureza, poluem cidades e alteram o clima da Terra (OLIVEIRA; MILIOLI, 2014, p.75).

${ }^{32} \mathrm{O}$ discurso do desenvolvimento sustentável inscreve as políticas ambientais nos ajustes da economia neoliberal para solucionar os processos de degradação ambiental e o uso racional dos recursos ambientais; ao mesmo tempo, responde à necessidade de legitimar a economia de mercado que resiste à explosão, à qual está predestinada por sua própria "ingravidez" mecanicista. Assim, precipitamo-nos para o futuro sem uma perspectiva clara para desconstruir a ordem antiecológica herdada da racionalidade econômica e para caminhar para uma nova ordem social, orientada pelos princípios de sustentabilidade ecológica, democracia participativa e racionalidade ambiental (LEFF, 1994).
} 
Zygmunt Bauman (1998) adverte que o capitalismo se reinventa e seduz, desperta desejo, consumismo e mercantiliza as relações sociais e tudo que possa ter valor e ser tomado como mercadoria, serviço ou produto. O mundo na era da globalização não é mais sólido, se tornou líquido e toma a forma que achar mais producente e for conveniente. Nesse mote, a mobilidade social, vem consubstanciada como a robustez do capitalismo num ano em que migrações em massa de países africanos para Europa e de países pobres da Ásia para os Tigres Asiáticos e economias em expansão. Um chamariz desse glamour da urbanização é medido pela desigualdade socioeconômica, inerente ao sistema. Afinal, para existir bilionários e milionários têm que haver muitos na miséria e exclusão.

Discorrer acerca de globalização é falar de problemas inerentes a esse processo excludente e pernicioso, para quem está fora do circuito do poder econômico, político e social de destaque para se sobrepor a supremacia do sistema em voga. Enquanto existir desigualdade entre seres dotados de liberdade e de razão, haverá necessidade de ética. Embora, essa não tenha poder para impor a igualdade econômica, ela tem o poder de lembrar continuamente aos "mais iguais" o dever de respeitar o âmbito da liberdade dos demais na busca do bem-estar e da própria felicidade. Isso é de fundamental importância e relevo, para poder dar amplitude aos que não têm voz ativa e poder de intervir nos eixos temáticos mais influentes do meio social. "Mesmo que diferentes, todos são humanos, têm necessidades básicas semelhantes que, por mecanismos de mercado e livre circulação de mercadorias, serviços e capitais acabam por excluir maciça parcela da população mundial de direitos humanos mínimos" (FELIPE, 2003, p.85).

Nesse contexto, vê-se que uma alta concentração de recursos e acesso a eles têm desencadeado inúmeros conflitos e tensões entre os povos no momento em que a globalização só expande seus tentáculos aprofundando problemas entre países e dentro desses e suas regiões, com enfoque para os dilemas da homogeneização cultural que impede um diálogo aberto e franco sobre o neoliberalismo e suas implicações:

Todos devem ter como objetivo compartilhar os benefícios e custos do uso de recursos entre comunidades e grupos interessados, entre as comunidades pobres e ricas, entre as gerações presentes e futuras. Cada geração deve deixar para sua sucedânea um mundo pelo menos tão diverso e produtivo quanto aquele que herdou. A proteção dos direitos humanos e da natureza é responsabilidade de âmbito mundial que transcende as fronteiras culturais, ideológicas e geográficas. A responsabilidade é tanto coletiva como individual (AVELINE, 1999, p.8).

Outrossim, discorrer acerca de direitos humanos e globalização no século XXI é trazer a lume várias questões e suas causas, origens e possíveis respostas diante do conhecimento que se tem para tentar obstar os efeitos adversos do massacre ambiental, da exploração do homem pelo homem, da usurpação dos recursos naturais dos países pobres pelos ricos, dentre outros que deveriam estar em primazia na agenda política e da iniciativa privada. Desse modo, importantíssimo esclarecer o que é dignidade da pessoa humana:

Há quem aponte para o fato de que a dignidade da pessoa não deve ser considerada exclusivamente como algo inerente à natureza humana (no sentido de uma qualidade inata pura e simplesmente), isto na medida em que a dignidade possui também um sentido cultural, sendo fruto do trabalho de diversas gerações e da humanidade em seu todo, 
razão pela qual as dimensões natural e cultural da dignidade da pessoa se complementam e interagem mutuamente, guardando, além disso, relação direta com o que se poderá designar de dimensão prestacional (ou positiva) da dignidade (SARLET, 2008, p.28).

Se a dignidade da pessoa humana requer uma prestação positiva do Estado ${ }^{33}$ (União, Estados e Municípios) há, também, uma contrapartida por parte do exercício legítimo da cidadania por parte do povo. Esse povo que é composto de histórias e culturas também têm, por sua vez, o dever se zelar pelos bens públicos e pelas condições de vida para as gerações vindouras. Em outras palavras, a geração que habita um dado espaço nesse momento tem o dever de assegurar o equilíbrio ecossistêmico para o usufruto das gerações do porvir. Nesse caso, há de se trabalhar a dimensão ambiental, social, urbana, rural, em sua totalidade para contemplar a prestação positiva de dignidade para como legado civilizacional:

O que se percebe, em última análise, é que onde não houver respeito pela vida e pela integridade física e moral do ser humano, onde não houver limitação do poder, enfim, onde a liberdade e a autonomia, a igualdade (em direitos e dignidade) e os direitos fundamentais não forem reconhecidos e minimamente assegurados, não haverá espaço para a dignidade da pessoa humana e esta (a pessoa), por sua vez, poderá não passar de mero objeto de arbítrio e injustiças (SARLET, 2008, p.35).

A limitação de poder do próprio Estado, o respeito pela vida e pela integridade física, a livre expressão e autonomia, igualdade formal e material, visam assegurar a concretização dos direitos fundamentais para impedir a arbitrariedade do mercado e suas injustiças. A regulação estatal dos excessos cometidos pela economia no neoliberalismo, a fiscalização adequada de recursos financeiros e transações internacionais, visando diminuir as gritantes diferenças entre seus cidadãos, facilitando o acesso a direitos e assegurando o exercício de condições básicas para quem antes estava à margem da sociedade:

A recente crise financeira global, cujo incêndio ainda não foi debelado de todo, serviu para mostrar o quanto a teoria econômica dominante estava fora da realidade - o que, aliás, tem precedentes históricos (como na Grande Depressão). A livre mobilidade do capital e a desregulamentação financeira tornaram os países em desenvolvimento extremamente vulneráveis aos choques globais. Ficou provado que quanto mais aberta e a economia, maior a necessidade de proteção social do Estado e não o contrário. Qualquer que seja o rumo que o novo estruturalismo venha a tomar no futuro, o ponto de partida, sem dúvida, devera ser a redefinição das funções do Estado, particularmente em relação a sua inserção no mundo globalizado (PEREIRA, 2006, p. 140).

A inserção social, a eliminação das disparidades de renda, diluir a exclusão, miséria e dicotomias decorrentes do processo capitalista é dever do Estado que faça por seus cidadãos menos desprovidos o controle desses excessos. Além disso, na era da expansão comercial, das fronteiras apenas para alguns grupos e segmentos sociais, da produção em larga escala, das questões

\footnotetext{
${ }^{33}$ Não obstante, a transição para um desenvolvimento sustentável não se fará por força da necessidade ou do instinto de sobrevivência da sociedade. A história mostrou ad nauseam e ad mortem como as ideologias, os interesses e o poder são capazes de burlar os mais elementares princípios morais de convivência pacífica entre os humanos. Estas mudanças não serão alcançadas sem uma complexa estratégia política, orientada pelos princípios de uma gestão democrática do desenvolvimento sustentável, mobilizada pelas reformas do Estado e pelo fortalecimento das organizações da sociedade civil (LEFF, 2011, p.64).
} 
humanitárias e ambientais transfronteiriças, do sistema financeiro planetário, da informatização do saber, da aplicação de tecnologia em diversos setores, engendrando um emblemático rol de questões das mais variadas ordens para respostas locais, regionais e globais que exigem solução urgente. Os direitos humanos na modernidade estão à deriva por causa desses e outros perigos que o excesso de intervenção antrópica incutiu na teia da vida:

Entretanto, há caminhos viáveis pra sanar parcela considerável dessa falta de recursos. Especialistas apontam que a melhor solução é o imposto progressivo anual sobre o capital, afinal ele tem mostrado robustez através do número de bilionários e milionários ${ }^{34}$, dos lucros recordes de bancos. Com a taxação de grandes fortunas, heranças e lucros, é possível evitar a espiral desigualadora sem fim e ao mesmo tempo preservar as forças da concorrência e os incentivos para que novas acumulações primitivas se produzam sem cessar. Por exemplo, menciona-se a possibilidade de uma tabela de cálculos de tributos com taxas limitadas a $0,1 \%$ ou $0,5 \%$ ao ano para patrimônios inferiores a 1 milhão de euros, 1\% para aqueles entre 1 e 5 milhões de euros, $2 \%$ para os que estão entre os 5 e 10 milhões de euros, podendo subir até $5 \%$ ou $10 \%$ ao ano para os patrimônios entre centenas de milhões ou bilhões de euros. Isso permitiria conter a progressão ilimitada da desigualdade mundial, pois mostra concretamente que a riqueza produzida mundialmente está se concentrando nas mãos de um seleto grupo de pessoas, crescendo num ritmo insustentável no longo prazo, que deve alarmar mesmo o mais fervoroso defensor do mercado autorregulado. A experiência histórica indica, além disso, que desigualdades de riquezas tão desmedidas não têm tanta relação com o espírito empreendedor- o que refuta o aclamado termo "meritocracia" - e não apresentam nenhuma utilidade para o crescimento, pois ele é amorfo, assimétrico e injusto (PIKETTY, 2014, p.556).

Os direitos humanos devem agir de forma integrada para dar ou apontar soluções e respostas que transcendem o ordenamento jurídico conceitual típico. Por isso, a transdisciplinaridade é requisito essencial para tecer uma macroestrutura para compreensão dos dilemas e dicotomias existentes hoje.

Conforme o excerto adiante, a falta de racionalidade ambiental e o pensamento a curto prazo de gestores públicos e iniciativa privada conduzem a um abismo a sociedade presente:

Nós somos herdeiros de um tipo de sociedade, hoje globalizada, que já perdura por trezentos anos, e que se propôs algo inaudito na história: explorar a Terra e todos os seus recursos e serviços no solo, no subsolo, nos rios e nos oceanos de forma ilimitada. Faz isso para aumentar mais e mais a oferta de produtos para o consumo ou então para acumular riqueza de forma crescente e no tempo mais curto possível (BOFF, 2009, p.108-109).

Os conflitos decorrentes da extrema falta de cuidado com o outro e com os recursos naturais estão trazendo um sortilégio de malefícios sociais, econômicos, ambientais, e outros que se somam para retroalimentar tensões e disputas em pleno século XXI. Água doce, matéria-prima, elementos cruciais para manter o ritmo do crescimento econômico a todo custo traz um chamado "mercado global" nada mais é do que uma rede de máquinas programadas para atender a um

\footnotetext{
${ }^{34} \mathrm{O}$ número de bilionários no mundo aumentou $7 \%$ e atingiu 2.325 em 2014, um novo recorde, de acordo com um "Censo de bilionários" publicado nesta semana pelo banco suíço UBS e pela consultoria de Hong Kong Wealth-X. No Brasil, são 61 ricaços, com US\$ 182 bilhões no total, segundo esse levantamento. Outro ranking divulgado recentemente, da revista "Forbes Brasil", fala em 150 bilionários no país e considera a fortuna em reais, não em dólares (ABE, 2014).
} 
único princípio fundamental: o de que o ganhar dinheiro deve ter precedência sobre os direitos humanos, a democracia, a proteção ambiental e qualquer outro valor (CAPRA, 2002, p. 268). Sendo imperioso recorrer a uma nova ética e racionalidade ambientais para projetar, bem como estimular qual e como será o futuro diante das tragédias socioambientais que, por hora, já são manifestas.

\section{MODERNIDADE E CONFLITOS AMBIENTAIS: POR UMA NOVA ÉTICA E RACIONALIDADE AMBIENTAIS}

Lançar novos matizes que subsidiem uma nova era para a humanidade é preciso, poeticamente falando, quebrar todas os paradigmas e transpor as barreiras impostas pelo status quo. A pós modernidade será composta de instrumentos e conhecimentos múltiplos que possibilitem a sociedade.Satisfazer as necessidades e as aspirações humanas é o principal objetivo do desenvolvimento.

Nos países em desenvolvimento, as necessidades básicas de grande número de pessoasalimento, roupas, habitação, emprego- não estão sendo atendidas, pois não há distribuição de renda que seja compatível para pagar pelo alimento, nem acesso a terra que recai na falta de reforma agrária. Além dessas necessidades básicas, as pessoas também aspiram legitimamente a uma melhor qualidade de vida, com acesso digno a saúde pública de qualidade, educação básica e superior, saneamento básico e tratamento de esgotos, acesso a água potável, mobilidade urbana, melhorias para quem mora no campo.

Num mundo onde a pobreza e a injustiça são endêmicas, sempre poderão ocorrer crises ecológicas e de outros tipos, pois há uma alta concentração de poder, terra, conhecimento e capitais nas mãos de poucos. Para que haja um desenvolvimento sustentável, é preciso que todos tenham atendidas suas necessidades e lhes sejam proporcionadas oportunidades de concretizar suas aspirações a uma vida melhor (NOSSO FUTURO COMUM, 1988, p.47).

A eliminação das contradições encontradas no âmago das sociedades ocidentais contemporâneas requer um arcabouço sociológico, antropológico e filosófico novos. Não apenas ruptura pontuais e descontínuas, mas sim uma adesão coletiva, planejamento de Estado e com execução e cobrança para rede privada vislumbrando uma radical alteração comportamental:

\footnotetext{
Outras manifestações alternativas ao modelo hegemônico surgem aqui e acolá. Muitas delas vislumbram a necessidade de tornar mais democrático o acesso à base material da existência. É verdade que as convenções internacionais ainda não representam essa possibilidade em sua plenitude, em especial quando prescrevem relações desiguais entre os países partes, mas certamente representam alternativas mais saudáveis que a da guerra, além de permitirem que países com menor condição econômica e, especialmente militar, expressem seus pontos de vista com sucesso nos foros multilaterais (RIBEIRO, 2010, p.78).
}

As realizações de Cúpula dos Povos, Conferências Climáticas, Fórum Social Mundial, cooperativas, bancos de microcrédito e dinheiro alternativo, têm possibilitado a inserção formal de milhares de pessoas no meio social, empoderando famílias e contribuindo para eliminação da pobreza extrema. O diálogo, poder de voto e decisão originados pelos representantes dos países nos tratados e convenções internacionais, criam uma atmosfera de negociação na qual é possível 
obter, sem guerras, ganhos promissores para as searas social, ambiental e econômica na interminável jogo de poder por mercado consumidor e fornecedores de insumos. Nessa esteira, uma nova racionalidade ambiental que abarque as diversas dimensões do ser, da relação homem-natureza, natureza-homem, do todo e suas partes recai numa ética conceitual que está sendo tecida para fugir ao mero antropocentrismo.

Assim sendo, se reforça a premissa crucial da dignidade da pessoa humana porque não pode existir inclusão de quem nunca estive dentro, de quem só vive na marginalização socioeconômica e sofrendo injustiça ambiental, de tal forma que na qualidade intrínseca e distintiva reconhecida em cada ser humano que o faz merecedor do mesmo respeito e consideração por parte do Estado e da comunidade, implicando, nesse sentido, um complexo de direitos e deveres fundamentais que assegurem a pessoa tanto contra todo e qualquer ato de cunho degradante e desumano, como venham a lhe garantir as condições existenciais mínimas para uma vida saudável, além de propiciar e promover sua participação ativa e co-responsável nos destinos da própria existência e da vida em comunhão com os demais seres humanos (SARLET, 2008, p. 37-38).

Em termos gerais, o paradoxo oriundo da base de acumulação e concentração de capitais para medir o desenvolvimento de um povo, pautando em índice econômico o bem estar social deve ser refutado, pois esse método avaliativo é distorcido e não dá vazão para aferir qualitativamente uma nação. Conectado a isto, num contexto político, econômico, sócio-cultural e ambiental, essa tendência trouxe algumas inquietações. Então, meio ambiente e desenvolvimento não se constituem questões isoladas ou desconectas, mas estão interligadas e por conseguinte não podem ser tratadas separadamente dado a (trans)interdisciplinaridade. A questão, portanto, tem um fundo teórico de extrema importância: meio ambiente e desenvolvimento constituem parte de um sistema complexo de causa e efeito, estabelecendo conexões e uma simbiose difícil de compartimentalizar.

A partir dessa leitura, em que os desgastes ambientais e os padrões de desenvolvimento econômico interligam-se a vários fatores sociais e econômicos, bem como as características sistêmicas transcendem os limites internos e geográficos das nações, a questão da segurança dos ecossistemas passa a ganhar uma importância crucial. Nesse sentido, a necessidade de interligação das várias ciências e de se interpretar integradoramente os conceitos e teorias para na prática ter uma aplicação mais acertada (MILIOLI, 1999, p.73).

Exposto isso, uma reordenação da base produtiva e do que é primordial para a humanidade entra em cena. O parâmetro é a felicidade e qualidade de vida, não mais a acumulação de recursos e bens materiais, perfazendo um novo trajeto que possibilita a economia ecológica lançar um olhar crítico sobre a degradação ecológica energética resultante dos processos de produção e consumo, tentando sujeitar o intercâmbio econômico às condições do metabolismo geral da natureza, incutindo os passivos ambientais no processo produtivo e mudando a relação do público consumidor com o consequente resíduo sólido gerado (LEFF, 2011, p.44).

Não obstante, o antagonismo desempenhado por mecanismos de mercado que insistem em perpetuar o estabilishment e há contracenso nas políticas públicas que, grosso modo, nem sempre privilegiam a longo prazo a extração, distribuição e solidariedade entre os detentores da biodiversidade:

Na confluência dos múltiplos interesses em jogo na transição para uma ordem econômica sustentável, abre-se um amplo espaço de concordâncias e um espectro de modelos sociais alternativos. Neste processo, parece pouco realista enfrentar o projeto neoliberal tão somente com os valores de uma ética conservacionista. Um dos grandes desafios que 
a sustentabilidade enfrenta é a construção do conceito de ambiente como um potencial produtivo sustentável; isto é, materializar o pensamento complexo numa nova racionalidade social que integre os processos ecológicos, tecnológicos e culturais, para gerar um desenvolvimento alternativo (LEFF, 2011, p.60).

Repensar o meio ambiente significa alterar radicalmente o estabilishment e a ideologia do capitalismo selvagem. Transpor as barreiras do mero consumismo ${ }^{35}$ e mecanismos de dominação instrumentalizado pela globalização. Viver numa cidade ou no campo, desde que com dignidade humana, pautado por novos valores sociais alicerçados no comprometimento com o próximo e com o outros seres vivos, acredito que uma sociedade nova requer isso. Planejamento, organização e execução de planos que envolva todos os setores de uma sociedade democrática e sustentável são regras básicas para se tecer uma nova era em termos de crescimento e desenvolvimento sociodemográfico:

Constatamos, então, que há muitos tipos de sociedade, com suas instituições e normas legais que organizam de forma diferente os relacionamentos com a natureza. Em algumas, especialmente nos povos originários, os indígenas, vigora uma profunda comunhão com a natureza e um cuidado natural para com os ecossistemas. Disso resulta uma grande harmonia entre ser humano e meio ambiente. Há outras que quebram essa harmonia. Em geral, por onde passa, o ser humano deixa um rastro de irresponsabilidade e falta de cuidado (BOFF, 2009, p.108).

Nesse mote, há limites para o crescimento exponencial dos capitais e fundação e subsistência das condições ideais de vida numa cidade para seres humanos. Esses limites da urbanização e fatores limitantes de recursos são: água potável, saneamento básico, tratamento de água e esgoto, destinação adequada de resíduos sólidos, mobilidade urbana, auto sustentação em termos de emprego e renda, qualidade de vida, bem-estar, dentre outros sendo fundamental uma gestão ambiental participativa:

A gestão ambiental participativa está propondo, além da oportunidade de reverter os custos ecológicos e sociais da crise econômica, a possibilidade de integrar a população marginalizada num processo de produção para satisfazer suas necessidades fundamentais, aproveitando o potencial ecológico de seus recursos ambientais e respeitando suas identidades coletivas. Assim estão surgindo "iniciativas descentradas" para construir uma nova racionalidade produtiva, fundada em práticas de manejo múltiplo, integrado e sustentado dos recursos naturais, adaptadas às condições ecológicas particulares de cada região e aos valores culturais da comunidade (LEFF, 2011, p.63).

Ainda assim, há fissuras que devem ser levadas em consideração na concepção de resoluções dos conflitos socioambientais:

Não obstante, a transição para um desenvolvimento sustentável não se fará por força da necessidade ou do instinto de sobrevivência da sociedade. A história mostrou ad

\footnotetext{
${ }^{35}$ A Terra já ultrapassou em $25 \%$ sua capacidade de carga e regeneração. Não iremos enfrentar uma grande crise. Já estamos dentro dela. Estudos da Universidade de Campinas (São Paulo) revelaram que bastou o aumento no clima do Estado de São Paulo e no sudeste de Minas Gerais para fazer com que as flores de café caíssem antes de formarem o grão. E a Embrapa mostrou o mesmo em relação ao milho, ao feijão e a soja (BOFF, 2009, p.110).
} 
nauseam e ad mortem como as ideologias, os interesses e o poder são capazes de burlar os mais elementares princípios morais de convivência pacífica entre os humanos. Estas mudanças não serão alcançadas sem uma complexa estratégia política, orientada pelos princípios de uma gestão democrática do desenvolvimento sustentável, mobilizada pelas reformas do Estado e pelo fortalecimento das organizações da sociedade civil (LEFF, 2011, p.64).

O que explica uma luta de classes, uma dicotomia de interesses, ensejando um amálgama de ideais, necessidades, desejos e sonhos que estão permeados por culturas diferentes e sujeitos diversos. Essa divisão social engendra uma hierarquia que tende a sedimentar os poderios econômicos, cultural, geopolítico, estratégico e de perpetuação das classes dominantes ${ }^{36}$. O que se tem é uma ascensão das cidades que ficam nos países ricos (Norte) em detrimento das megalópoles instaladas nos países periféricos (Sul). As externalidades ambientais e passivos causados pela industrialização têm anuência do Estado, pois o mesmo mantém relações de poder com a iniciativa privada.

Nesse diapasão, há uma nítida performance da racionalidade econômica em face da racionalidade ambiental, deixando para a tecnologia resolver os problemas que ela mesma engendrou. Eis a falsa crença de que os problemas do capitalismo exacerbado serão por ele mesmo solucionados. Ainda, conforme Leff (2001, p.59), "existem processos ecológicos e valores humanos impossíveis de serem reduzidos ao padrão de medida do mercado".

Como pressuposto da globalização, o neoliberalismo advém da alta capacidade de adaptação do capital e sua sinuosidade para transformar quaisquer coisa, pessoa, material ou objeto em mercadoria que seja passível de lucro. No Brasil e no mundo, observa-se uma fuga de capitais e cérebros para os países que possam ofertar insumos e mão-de-obra barata. Lógico que a "flexibilização" e os direitos trabalhistas e ambientais conquistados ao longo de séculos são ultrajados nesse processo de circulação de mercadorias e serviços:

\begin{abstract}
O tipo de indústria que mobiliza os ciclos econômicos no Brasil necessitou e necessita concentrar a renda para viabilizar o padrão de consumo dos países capitalistas centrais e isso pode ser visto em todo o território nacional com o vigor de largos nichos de segmentação social. Um sistema tributário que concentra assustadoramente a renda não pode produzir senão um cenário social de desigualdade (BARBOSA, 2007, p.3).
\end{abstract}

Nessa toada, o discurso do Desenvolvimento Sustentável como meio da autopromoção dos povos com respeito à natureza foi concebido para perpetuar o capitalismo. Todavia, ainda assim, é considerado um avanço, mesmo não tendo sobressaído o conceito original de ecodesenvolvimento, pois poria fim a era do capitalismo predatório. Mas, há teóricos que defendem o DS dizendo que ele erradica a pobreza e criando alternativas de desenvolvimento de base local, participativa e descentralizada (LEFF, 2001, p.61). Rompendo com a lógica dominante, uma gestão ambiental que trabalhe o desenvolvimento diferente para os países do terceiro mundo que devem trabalhar melhor seus recursos e não seguir, meramente, o padrão hegemônico euroamericano que foi imposto pelo neoliberalismo (LEFF, 2001, p.65).

\footnotetext{
${ }^{36}$ Historicamente existem conflitos entre as classes sociais que existem na sociedade. Dentro de uma estrutura social há estratificações em que a classe dominante possuirá e controlará os estoques dos recursos econômicos (ou meios de produção), e controlará, dessa maneira, o destino é a burguesia, que detém o capital, enquanto a classe subordinada é o proletariado (cujos membros têm apenas a habilidade para o trabalho, que eles devem vender para sobreviver). A exploração ocorre por meio da expropriação da mais-valia, o que significa dizer que a recompensa do proletariado por vender seu trabalho vale menos do que o valor de troca do produto quando vendido. Esses conflitos são minimizados através de mecanismos ideológicos (instituições educacionais, religião e mídia de massa) existentes na sociedade. (EDGAR; SEDGWICK, 2003, p. 58-59).
} 


\section{CONSIDERAÇÕES FINAIS}

A crise socioambiental engendrada no Brasil é semelhante, em muitos aspectos, a mesma crise que perpassa o planeta Terra. Uma premissa universal é a que a civilização ocidental e toda sua conjectura trouxe inúmeras transformações para o meio ambiente na qual está inserida. Ao longo da história, houve uma acumulação contínua de conhecimentos e capitais para culminar no capitalismo que se tem hoje. Com a formação do Estado Moderno e as profusões da revolução industrial houve uma acentuada sistematização da crise ecológica e social que permeia o cotidiano da humanidade atualmente.

As evoluções técnico-científicas e os problemas decorrentes do modo de produção capitalista, o extremo uso e dependência dos recursos naturais e energéticos, trouxeram uma gama de degradações sociais, ambientais, geográficas, físicas e humana. Mediante esse cenário desolador, há uma congênita e famigerada crise que se instala nos quatro cantos do mundo nos diversos campos supramencionados.

Os obstáculos encontrados são os mais diversos, dentre eles podem ser citados: perda de direitos, flexibilização de direitos, mão-de-obra escrava, trabalho infantil, prostituição, tráfico internacional de seres humanos, poluição ambiental, devastação da fauna e flora, poluição dos recursos hídricos, questões de mobilidade urbana, violência, fome, desigualdade, exploração Norte-Sul e dentro das regiões desses próprios países. Não obstante, as possibilidades para um futuro alternativo já são, em alguma medida, encontradas. Investimento em energia renovável; tratamento de água e esgoto com alcance $100 \%$, educação pública de qualidade e universal;investir em pessoas e seus talentos e não em instituições financeiras; erradicar a pobreza extrema e a desigualdade entre países e dentro deles; diminuir o consumismo; massificar o acesso a tecnologias de baixo custo e alto impacto para populações carentes; empoderar pessoas; distribuir recursos a baixo ou zero custo para países pobres, possibilitando pontes e conexões para um futuro diversificado e pautado nas relações humanas de qualidade.

Uma nova era para a humanidade pode ser composta por uma sociedade que tenha ações concretas de um novo porvir. Um mundo diferente é possível se houver comprometimento e engajamento político, civil, privado, e todos os atores sociais se unirem para utilizar os mecanismos já existentes para cada localidade ser transformada. A mudança pode e deve acontecer, pois o mundo está beirando o caos e já padece de inúmeros conflitos nas dimensões humana, ambiental, cultural, psicológica, cidade, política, levando ao colapso civilizacional. Alternativas de desenvolvimento e manutenção das condições de vida na Terra são apontadas por especialistas e estudiosos.

A questão recai bastante na aceitação política e privada, já que têm um peso acentuado na disseminação de novas práticas e ideias, e no interesse em multiplicar, dinamizar e ratificar esses instrumentos que visam aniquilar os problemas que assolam a humanidade. É intrínseco da ideologia capitalista e neoliberal demarcar territórios para exploração e zonas de mercantilização das mercadorias. Esse processo torna objeto não só os insumos e mercadorias decorrentes da matéria-prima natural e transformada, mas os próprios seres humanos. Romper essas barreiras e limitações do sistema significa transpor o sistema e criar uma nova base para disseminar poeticamente e enfaticamente laços de humanidade e respeito para com a diversidade em todas as suas formas e variáveis. 


\section{REFERÊNCIAS BIBLIOGRÁFICAS}

ABE, Maria Carolina. Número de bilionários no mundo chega a 2.325, diz estudo; no Brasil, são 61. Disponível para acesso em: http://economia.uol.com.br/noticias/redacao/2014/09/17/ numero-de-bilionarios-no-mundo-chega-a-2325-diz-estudo-no-brasil-sao-61.htm. Publicado em 17/09/2014. Acesso em 12 de março de 2016.

ARENDT, Hannah. Entre o passado e o futuro. Ed. Perspectiva, São Paulo, 1972.

AVELINE, C. C. A vida secreta da natureza: uma iniciação à Ecologia Profunda. Furb, Blumenau, 1999.

BAUMAN, Zygmunt. Globalização: as consequências humanas. Zahar, 1998.

BARBOSA, N. C. A economia solidária como política pública: uma tendência de geração de renda e ressignificação do trabalho no Brasil: Cortez, 2007 (p.21-88).

BOFF, L. A opção Terra: a solução para a terra não cai do céu. Record, Rio de Janeiro, 2009.

CAPRA, F. As Conexões Ocultas : ciência para uma vida sustentável. Editora Cultrix, 2002.

Comissão Mundial sobre Meio Ambiente e Desenvolvimento. NOSSO FUTURO COMUM. FGV, Rio de Janeiro, 1988.

DELPHIM, C.F.M. O patrimônio natural do Brasil. Disponível em: http://portal.iphan.gov.br/ baixaFcdAnexo.do?id=418. Acesso em 27 de abril de 2015.

DIEGUES, A. C. S. Desenvolvimento sustentável ou sociedades sustentáveis: da crítica dos modelos aos novos paradigmas, São Paulo em perspectiva, 1992. Disponível para acesso em: http:// produtos.seade.gov.br/produtos/spp/v06n01-02/v06n01-02_05.pdf. Acesso em 20 de maio de 2015.

EDGAR, Andrew; SEDGWICK, Peter. Teoria Cultural de A a Z: conceitos-chave para entender o mundo contemporâneo. Tradução Marcelo Rollemberg. São Paulo: Contexto, 2003.

El KHALILI, Amyra. Commodities ambientais em missão de paz - novo modelo econômico para a América Latina e o Caribe / Amyra El Khalili. - São Paulo, sp : Nova Consciência, 2009.

FELIPE, S. T. Por uma questão de princípios: Alcance e limites da ética de Peter Singer em defesa dos animais. Florianópolis, Boiteux, 2003.

GONÇALVES, C. W. P. Os (des)caminhos do meio ambiente. São Paulo, SP. Editora Contexto, 2002. HARVEY, D. Espaços de Esperança. Edições Loyola. São Paulo, 2009.

JAMESON, Fredric. O pós-modernismo e o mercado. In Um Mapa da Ideologia, Org. Slavoj Zizek. Contraponto, Rio de Janeiro, 1996.

MILIOLI, G. Abordagem ecossistêmica para a mineração: uma perspectiva comparativa para Brasil e Canadá. Tese PPGEP, UFSC, Florianópolis, 1999.

MORIN, E.; K., A. B. Terra-Pátria. Porto Alegre, Sulina, 1995.

MORIN, Edgar. As duas globalizações: complexidade e comunicação, uma pedagogia do presente. Col. com.13, 2a ed. Juremir Machado da Silva (org.) Joaquim Clotet. EDIPUCRS, SULINA. Porto Alegre, 2002.

OLIVEIRA, I. R.; MILIOLI, G. Sustentabilidade urbana \& Ecossistema: relações entre a sociedade, o desenvolvimento e o meio ambiente nos municípios. Curitiba, Juruá, 2014. 
PEREIRA, José Maria Dias. Uma breve historia do desenvolvimentismo no Brasil. Cadernos do Desenvolvimento. - Ano 1, n.1 (2006) Rio de Janeiro: Centro Internacional Celso Furtado de Políticas para o Desenvolvimento, 2006. CADERNOS do DESENVOLVIMENTO, Rio de Janeiro, v. 6, n. 9, p.121-141, jul.-dez. 2011. Disponível em: http://repositorio.cepal.org/bitstream/ handle/11362/11134/1/090007015_es.pdf.

PIKETTY, Thomas. $\mathbf{O}$ capital no século XXI. 1 ed. Rio de Janeiro. Intrínseca, 2014.

RATTNER, Henrique. Globalização em direção a um mundo só? Estudos avançados 25. São Paulo: USP, 1995.

RIBEIRO, W. C. Geografia política e gestão internacional dos recursos naturais. Dossiê Teorias Socioambientais. Estud. av. vol.24 no.68 São Paulo 2010. Disponível para acesso em: http://www. scielo.br/scielo.php?pid=S0103-40142010000100008\&script=sci_arttext. Acesso em 04 de maio de 2015.

SARLET, I. W. As dimensões da dignidade humana: uma compreensão jurídico-constitucional aberta e compatível com os desafios da biotecnologia. In: Direitos Fundamentais e biotecnologia. Orgs. Ingo Wolfgang Sarlet, George Salomão Leite. São Paulo: Método, 2008.

LEFF, E. Saber Ambiental: sustentabilidade, racionalidade, complexidade, poder. Petrópolis, RJ: Vozes, 2001.

LEFF, E. Saber ambiental: sustentabilidade, racionalidade, complexidade, poder. 8 ed. Petrópolis, RJ. Vozes, 2011.

, Ecología y capital. Racionalidad ambiental, democracia participativa y desarollo sustentable, México, Siglo XXI/Unam, 1994.

Ambiente y articulación de ciencias: los problemas del conocimiento e la perspectiva ambiental del desarollo, México, XXI, 1986. 